\title{
Economic and energy efficiency of forage grain conservation
}

\author{
Nikolay Nikolaevich Kuchin*, Aleksandr Vladimrovich Martyanychev, and Elena Vladimirovna Emelyanova \\ Nizhny Novgorod State Engineering and Economic University, 606340 Knyaginino, Nizhniy Novgorod region, Russia
}

\begin{abstract}
The use of dry preparations is a cheap and environmentally safe method of feed chemical conservation. This can be proved by the results of economic and energy assessment of methods for preserving forage grain, performed using generally accepted methods. The analysis of various methods of preserving, storing and preparing for feeding raw forage grain showed that flattening, chemical preservation and storage in anaerobic conditions was significantly cheaper and less energy intensive than drying it to standard humidity and storing it in the open air. This method is comparable to storing grain of standard humidity, removed in favorable weather conditions and prepared for feeding by grinding it on a hammer mill. The analysis result seems logical due to lower energy costs when replacing grain crushing with flattening. In addition, the forage grain prepared in this way corresponds much to the animals' physiological needs, and its preparation reduces the physical loss of feed.
\end{abstract}

\section{Introduction}

Chemical conservation has proved its effectiveness in preserving the quality and initial nutritional value of green feeds $[1$, p. 3]. This technological method for raw grain conservation has its own characteristics due to the distinctive properties of the preserved material. Its main characteristic feature is the moisture content, which should not exceed $40 \%$ for raw flattened grain. Its dry matter content is higher than in the silage and haylage mass of herbs.

Also, due to this reason it is incorrect to compare preservation of raw grain with silage and haylage, which is often done in the scientific literature. With such humidity of the conserved material, the vital activity of the bacterial microflora is extremely suppressed, but yeast and mold develop rapidly. To suppress their activity propionic acid or acid preparations with a mixed composition (where its proportion should be at least $17 \%$ ) are most suitable to use for chemical preservation of feed. Chemical preservative "Promir" produced by the Swedish concern PerstorpGroup has 18-23\% share of the propionic acid in the composition. Propionic acid suppresses the development of yeast and mold, blocks the enzyme systems of plant cells and microorganisms, prevents the formation of mycotoxins and minimizes grain losses during storage.

So, it corresponds in the highest degree to the task of the most complete preservation of feed quality during storage [2, p. 145]. At the same time, in recent years, the opinion has set [3, p. 199] that the use of chemical preservatives represents an increased danger for personnel and technical means used for their transportation, storage and use as well as significant costs for acquisition, introduction and safety. These reasons undoubtedly reduce their use.

The preference is now given to the use of biologics [4, p. 55; 5, p. 53]. However, it is overlooked that this characteristic is met only by liquid acid preparations, and not, for example, the salts of these acids, the use of which is not very dangerous.

Powdered preparations are more technologically advanced in terms of storage, transportation and application. The main obstacles to their use were their lower reliability compared with that of liquid acid preparations, the need for high doses (from 4 to $10 \mathrm{~kg} / \mathrm{t}$ of raw materials) and the lack of dosing devices for their application [6, p.79].

At the same time, all these obstacles can be eliminated when powdered sulfur which effectiveness was tested during corn silage is used as a chemical preservative [7, p.81]. The efficiency of using powdered sulfur was also established by the authors when preserving flattened raw barley grain [8, p. 64]. For its introduction, a dosing device was developed, which was tested under production conditions $[9$, p. 3$]$.

\section{Materials and Methods}

It is known [10, p. 7] that any production technology being improved can be recognized as effective when it provides savings in resources for the production of an item by increasing its quantity or improving quality, i.e., to get real production assessment.

We conducted the production test of the effectiveness of using powdered sulfur for conservation of raw flattened barley grain in JSC "Semyanskoe" in the Vorotynsky district of the Nizhny Novgorod region. The farm has a dairy and grain specialization of production. Livestock

\footnotetext{
*Corresponding author: kuchin53@mail.ru
} 
products constitute more than $60 \%$ of the revenue from the sale of all the household goods and services. The main livestock commodity product is milk. Brown Swiss cattle breed is used for its production. The herd counts 525 forage-fed cows.

The average annual milk yield from 1 forage-fed cow is about $6000 \mathrm{~kg}$ of milk. With such productivity, concentrated feeds occupy a significant place in the feed diet. The basis of concentrated feed is the own produced forage grain. Under favorable weather conditions, grain is harvested by direct combining at the humidity close to standard (14\%). The grain heap is cleaned from the litter materials and substandard with the help of the graincleaning separator BIS-100.

After the processing, the grain is stored in grain warehouses until it is used. If there is unfavorable weather during the harvesting period, the grain is threshed with high humidity. To bring it to the standard humidity, after sorting and cleaning, it is dried on an Agrex 250 grain dryer which is equipped with its own loading and unloading system. The grain is stored dry. It is prepared for feeding by crushing it with a hammer mill A1-DM2P55 M. Chemical preservation of grain with powdered sulfur is carried out while flattening it with the Volga $700 \mathrm{~K}$ flattener aggregated with a wheeled tractor MTZ82.1, and packaging it in plastics sleeve for hermetic storage.

The economic assessment of technologies was carried out according to the methodology of the Institute of forage research [11, p.83]. The authors used the primary accounting documents for the actual cost of material and monetary resources for the preparation of raw forage grains conserved with powdered sulfur when it is hermetically stored in plastic sleeves.

\section{Results}

The economic efficiency calculating of various methods of preserving and preparing forage grains is presented in Table 1.

Table 1. Economic efficiency of various methods of preserving and preparing forage grains, RUB / $t$

\begin{tabular}{|c|c|c|c|}
\hline \multirow{3}{*}{$\begin{array}{l}\text { Fodder } \\
\text { Indicators }\end{array}$} & \multicolumn{2}{|c|}{ Dry grains } & Raw grains \\
\hline & \multicolumn{3}{|c|}{ Conservation method } \\
\hline & Natural drying & Artificial drying & Using powedered sulfur \\
\hline Harvested area, га & \multicolumn{3}{|c|}{30} \\
\hline $\begin{array}{l}\text { Grain yield, t/ha: } \\
\text { with natural humidity }\end{array}$ & 2.38 & 2.9 & 2.9 \\
\hline in dry matter & 1.88 & 1.88 & 1.97 \\
\hline Natural grain yield, $\mathrm{t}$ & 71.4 & 75 & 75 \\
\hline Dry matter yield, $\mathrm{t}$ & 56.4 & 56.4 & 59.1 \\
\hline Cost of grain in the original mass & 3733 & 2949 & 2949 \\
\hline $\begin{array}{l}\text { Direct operating costs } \\
\text { In total }\end{array}$ & 2481.95 & 3710.27 & 2255.06 \\
\hline Including when: clearing the pile & 53.77 & 56.48 & - \\
\hline drying & - & 1225.61 & - \\
\hline threshing & 2428.18 & 2428.18 & - \\
\hline flattering & - & - & 1966.46 \\
\hline $\begin{array}{l}\text { preservative treatment and packaging in a plastic } \\
\text { sleeve }\end{array}$ & - & - & 288.6 \\
\hline Total: & 6214.95 & 6659.27 & 5204.06 \\
\hline In terms of $1 \mathrm{t}$ of dry matter & 7226.69 & 9513.24 & 7434.37 \\
\hline
\end{tabular}

They show that the yield of grain with high humidity (about $25 \%$ ) differs significantly (by more than 1/5) from the yield of grain harvested under favorable weather conditions with humidity close to the standard for aerobic storage (14\%). This mainly explains the difference in yield, since in the first case there are $140 \mathrm{~kg}$ of water per 1 ton of grain, and in the second $-250 \mathrm{~kg}$. In addition, certain weight losses are also observed in the process of grain maturation to full ripeness, i.e. when its humidity is brought to standard.

The difference in the yield of dry matter between dried and raw grain is due to the fact that the dry grain is cleaned from the weed and grain impurity (unripe, puny and crushed grain) during the preparation for storage. In total, these impurities may reach up $10 \%$ of the original grain weight. In raw grain, these impurities remain in the grain mass. This explains the differences in the yield of natural fodder and dry matter per unit of sown area between dry and raw grain. They show that the cost of growing and harvesting within the total cost of barley grain ranges from 44 to $60 \%$.

A smaller value refers to the dried grains, larger - to the grain harvested at standard humidity; and as for direct operating costs for conservation and preparation for feeding the proportionality is inverse. The cost of grain in the initially recorded mass consists of the cost of growing and harvesting grain, and is approximately equal per unit of acreage. However, when calculating the yield, it is naturally higher for dry grain, than for raw one (table 1). One can also explain the dependence size and structure of 
forage grain prime costs on the different methods of its storage and preparation for feeding. At any method of conservation and preparing for feeding of grains the main expenditure heading is preparing for feeding. In the structure of operating costs for grain that reached the standard humidity for outdoor storage in the field, it counts $97.8 \%$; for grain brought to the standard humidity by artificial drying $-65.4 \%$, and for chemically preserved grain for anaerobic storage $-87.2 \%$. At the same time, the cost of threshing (dry grain) was about 1/4 higher than the cost of flattening (raw grain).

The lowest cost at natural humidity was assessed for chemically preserved grain, the highest - for artificially dried to standard humidity. The difference equals to 10.89 RUB/t or $16.3 \%$. However, in terms of dry matter, i.e. when the nutritional value is approximately equal, the cost of dry and chemically preserved grain was almost equal (the difference is $178.6 \mathrm{RUB} / \mathrm{t}$ or $2.9 \%$ ). Replacing chemical preservation of raw grain with drying increased the cost of $1 \mathrm{t}$ of dry matter by 2078.87 RUB or $21.8 \%$, and in comparison with grain harvested at standard humidity - by 2286.55 RUB or $31.6 \%$ (table 1 ).

The economic assessment of production activity in the conditions of unstable pricing policy and the changeable rate of the ruble at the world market does not allow us to extend the obtained results for any long-term perspective and is only suitable for analyzing the current state.

Retrospective methods of the effectiveness of production activities assessment should not depend on certain market conditions and change only under the influence of alterations in material resources for its implementation.
Such assessment methods include the bioenergetics' method widely used in modern scientific research, which allows obtaining objective information about the effectiveness of feed production technologies in multivariant developments. When using it, all the variety of natural and material labor is expressed in units of energy: joules $(\mathrm{J})$, kilojoules $(\mathrm{kJ})$, megajoules $(\mathrm{MJ})$, gigajoules (GJ), etc. [12, p. 13; 13, p. 156].

To calculate the energy efficiency at the stage of production, storage and preparation of feed for use, the total energy costs are assessed. Determining the total energy intensity of forage harvesting technologies is carried out on the basis of technological maps, including harvesting of forage crops, processing of the mass and the technological process of its preservation, methods and modes of storage and preparation for feeding, taking into account all the material, energy and labor resources consumed.

Energy parameters of technologies for storing and preparing feed grains for feeding, calculated by the method of the Institute of feed research [10, p. 58] are presented in table 2 .

The data in the table show that the nutritional value of the conserved with powdered sulfur raw forage grains is higher than of dried ones: $2.5 \%$ as for the concentration of metabolizable energy (CME) in the dry matter, and $22.8 \%$ as for the crude protein content. Due to the dry matter higher yield (by $4.8 \%$ ) and its increased nutritional value, conserved raw grain received $7.5 \%$ more metabolizable energy and $28.6 \%$ more crude protein per unit of crop area, respectively, than the grain of standard humidity.

Table 2. Energy indicators of technologies

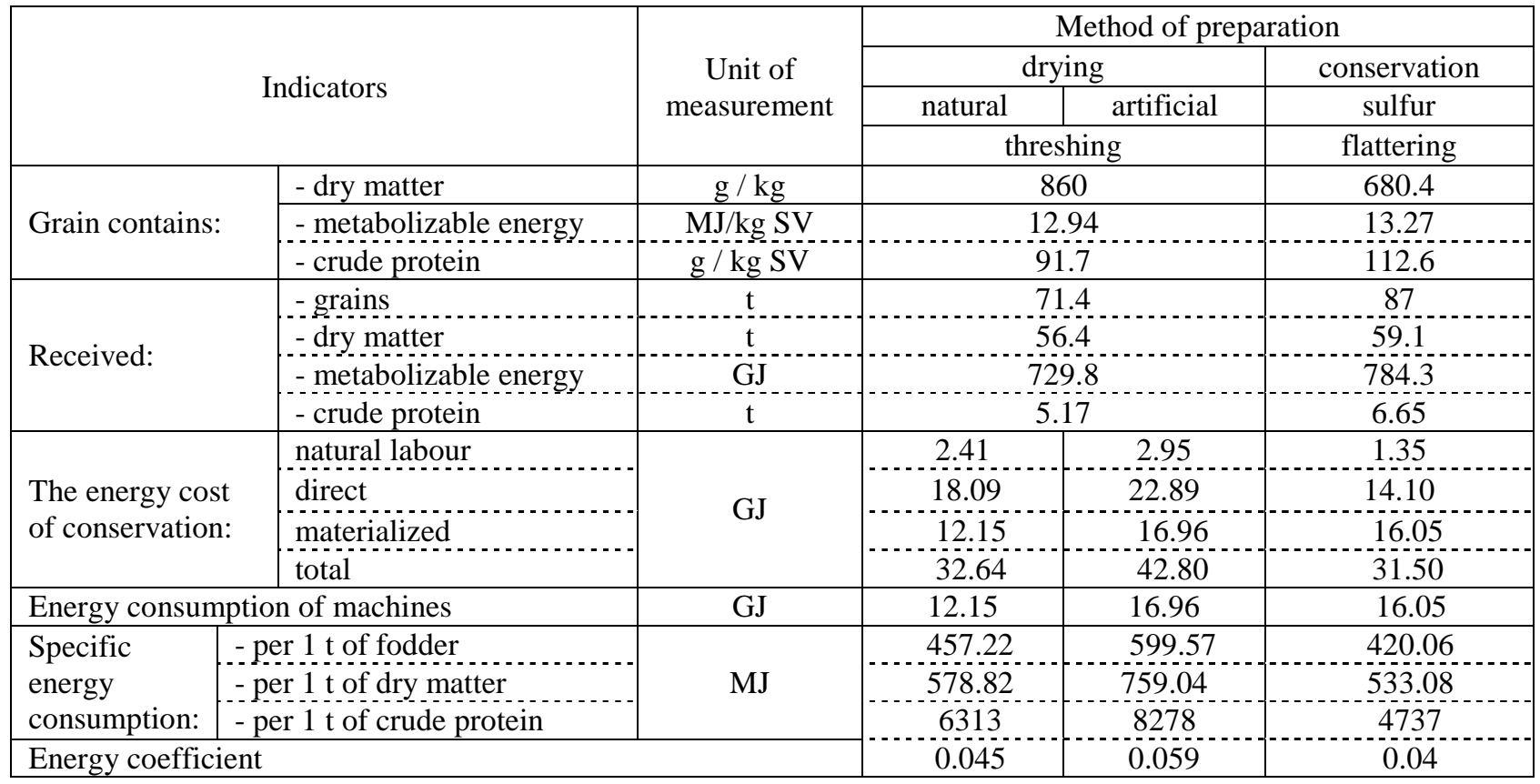

Comparison of the presented data shows that the least energy consuming technology for storing and preparing grain with high humidity for feeding is its flattening and storage in plastic sleeves. In the considered parameter this technology is comparable with the traditional technology of threshing grain of standard humidity, preparing for storage, storing it in warehouses and crushing it with subsequent feeding (the difference is $3.6 \%$ ).

The energy costs are the highest when it is not possible to prepare grain with standard humidity due to weather 
conditions, and it needs to be dried for storage in aerobic conditions. In this case, additional energy costs for drying grain increase by $10.16 \mathrm{GJ}$ or $23.7 \%$ per $1 \mathrm{t}$ of dry matter in comparison with grain harvested in a dry state. Preserving flattened grain with powdered sulfur and storing it in anaerobic conditions in plastic sleeves is in 11.3 GJ or $26.4 \%$ more economical in terms of energy costs (table 2).

Storage and preparation for feeding dry grain amounted for more than half (53.5-55.4\%) of direct costs in the structure of energy costs for conservation, i.e. fuel and electricity. Materialized costs were also a significant expenditure item, with the share of about $40 \%$. The remaining part of the costs is represented by the natural labor costs of workers engaged in the preparation of grain for storage and feeding.

When preserving raw flattened grain with powdered sulfur, about half $(50.9 \%)$ of energy costs amounted to the materialized costs or machines and equipment energy consumption. Direct energy costs were also significant (44.8\%), while the energy costs of natural labor were just over $4 \%$.

\section{Conclusion}

The attractiveness of method of the raw forage grain conservation with powdered sulfur followed by anaerobic storage can be explained by its technological advantages while using, increasing the nutritional value of grain fodder in comparison with the traditional drying it to the standard humidity for aerobic storage. It also gives the economic benefits in conditions of modern agricultural production. This was convincingly proved by production tests conducted at JSC "Semyanskoe" in the Vorotynsky district of the Nizhny Novgorod region. Application of this method not only increased the yield of dry matter in the production and preservation of raw grain by about 5 $\%$ (due to earlier harvesting and the inclusion of substandard grain fractions in the fodder), but also improved its energy and protein value.

The comparative analysis of the economic and energy efficiency of different methods of preserving and preparing grain for feeding showed the advantages of processing it with powdered sulfur followed by anaerobic storing it in a raw flattened form in plastic sleeves. In terms of material and energy costs for its implementation, this method is comparable to storing dry grain in warehouses, harvested under favorable weather conditions and prepared for feeding by threshing it with a hammer mill.

In comparison with the drying of raw grain and a similar method of preparation for feeding, the monetary costs of flattening, chemical preservation and anaerobic storage decreased by 21.8 per 1 ton of dry matter, while crushing grain harvested in favorable weather - by $31.6 \%$, energy costs - by 26.4 and $23.7 \%$, respectively.

\section{References}

1. M.T. Taranov, Chemical conservation offeed (Kolos, Moscow, 1982) 143 pp.

2. N.N. Kuchin, E.Yu. Gerasimov, Forage grain: ways of increasing its nutritional value and long-term storage (NGIEU, Knyaginino, 2016) 204 pp.

3. V.A. Bondarev, V.P. Klimenko, State and prospects of chemical preservation of herbs, in: Feed production: problems and solutions, pp. 199-203 (Moscow, 2008)

4. V.M. Kosolapov, V.A. Bondarev, V. P. Klimenko, Preparation of high-quality silage from meadow clover, Bulletin of the Russian Academy of agricultural Sciences, 4, 55-57 (2009)

5. Z.G. Weinberg, R.E. Muck, New trends and opportunities in the development and use of inoculants for silage, FEMS Microbiology Reviews, 19(1), 53-68 (1996)

6. V. A. Bondarev, V. M. Kosolapov, V. P. Klimenko, A. N. Krichevskiy, Preparation of silage and haylage with the use of domestic biological products (V.R. Williams research Institute of feed, Moscow, 2016) $212 \mathrm{pp}$.

7. R.F. Mangutov, R. F. Chaplygina, V.F. Gorshkov, A.V. Kharlamov, The use of inorganic sulfur in the preparation of corn silage, in: Rationing of meat cattle feeding, pp. 81-85 (Orenburg, 1985)

8. N.N. Kuchin, E.V. Emelyanova, The degree of acidification in the preservation of raw forage grains, Bulletin of NGIEI, 4(83), 64-73 (2018)

9. M.S. Zhuzhin, Development of a device for metered feeding of powdered preparation for food preservation, abstract of candidate dissertation (Knyaginino, 2017) 22 pp.

10. V.P. Geshel, Development of economic conditions in the production, processing and selling of livestock products, Economy of agricultural and processing enterprises, 3, 7-10 (1995)

11. A.A. Mikhailichenko, A.A. Kutuzova, U.K. Novoselov et al., Methodological guide on agro-energy and economic assessment of technologies and systems of feed production (Moscow, 1995) 174 pp.

12. S.A. Aliev, Agricultural energetic as the basis for increasing soil fertility and crop yields, in: Programming yields of agricultural crops in Siberia, pp. 13-17 (Novosibirsk, 1986)

13. A.A. Zhuchenko, A.D. Ursul, Strategy of adaptive intensification of agricultural production. The role of science in improving crop production efficiency (Kishinev; Shtinua, 1983) 304 pp. 